\section{ONCE UPON A TIME IN AMERICA...}

May is the month of the American Thoracic Society meeting. Once again, we return to California for one of the highlights of the annual calendar. To celebrate the rising submissions, and acceptances, from North American authors and the continued collaboration between the British and American Thoracic Societies, we felt it was an important step to deliver a North American themed issue for May. Indeed, as editors, we are Californian dreaming.

\section{FOR A FEW DOLLARS MORE...}

The Spaghetti Western described the chaotic and nihilistic landscape of the Old Wild West. In this issue, Nathan and colleagues introduce the spaghetti plot to highlight the ups and downs of lung function as idiopathic pulmonary fibrosis progresses remorselessly towards respiratory insufficiency albeit in slightly less barren environment than the Old Wild West (see page 429). However, defining whether an antifibrotic will "work" as IPF continues to progress is a perplexing problem which thus far has been reduced to the Dirty Harry approach of "Do I feel lucky?" Nathan and colleagues demonstrate that treatment with Pirfenidone has benefits despite the apparent progression of lung function decline suggesting lung function may not be the ideal way to determine an individual's response to therapy.

\section{CHIM CHIMENY, CHIM CHIM CHER-00...}

"Now as the ladder of life, Has been strung, You may think a sweep's, On the bottommost rung, Though I spends me time, In the ashes and smoke, In this ole wide world, There's no happier bloke". Dick Van Dyke's view on Household Air Pollution (HAP) was a little sanitized, but a more recent movie, Black Inside, a triptych telling the story of three women in three continents, ends with the message "Cooking shouldn't kill". Similarly cooking shouldn't damage your lungs. But it can, and in many places does. Heinzerling and colleagues examine data from the CRECER cohort study and RESPIRE trial of chimney stove intervention data, and demonstrate the negative effect of HAP on the developing lung function in children (see page 421, Editors' choice). How to deal with HAP is a controversial issue, as demonstrated by the pro-con editorials (see pages 391 and 393). However, Mary Poppins would be shocked to realise the consequences of her domestic service if she had to use an open indoor fire.
THE BIRDS...

Footsteps in the fog lead Alfred Hitchcock to Bodega Bay where Tippi Hedrin discovered to her terror that a bird in the hand is worth two in the bush. Walker Julliard and colleagues have made a similar observation with considerably better outcomes (see page 478). Assessing the results of 279 single lung transplant (SLT) they did not observe any difference in survival in patients with severe pulmonary arterial hypertension (PAH) suggesting that $\mathrm{PAH}$ itself should not be a contraindication for SLT. A real world example of a lung in the hand is worth two in the thorax.

\section{THE ABYSS...}

Although the Navy SEAL team felt abandoned and desolate during their time on an underwater oil rig searching for a sunken nuclear submarine, this is not far off the impact on the life of patients after critical illness as demonstrated in the SAIL study (see page 401). Although Rosuvastatin, given during critical illness in patients with with sepsis-associated ARDS, had no effect on 12-month survival, this trial showed that long term outcome of these patients is equally as difficult as being in an Abyss with survivors commonly experiencing impairments in physical function, mental health and quality of life. Identifying the most appropriate target population and phenotyping the patients at admission and deciding the best long term outcome measure is the challenge going forward as discussed in the accompanying editorial (see page 395). As important is the requirement to better understand the pathophysiology and mechanisms of ARDS to facilitate the translation of preclinical data into effective lung endothelial-specific therapies including advanced phenotyping of ARDS patients with as discussed by Millar and colleagues in their state of the art review (see page 462 ).

\section{SMOKING GUN...}

In the early 1980s, Hollywood responded to national anti-smoking campaigns by cutting the rate at which its stars lit up on-screen to just 4.9 times per hour, significantly less that the $1950 \mathrm{~s}$ rate of 10.7 per hour. But recently, the silver screen rate has shot back up to 10.9 per hour. ${ }^{1}$ Perhaps Hollywood needs to consider a population-based proactive tobacco treatment to increase engagement in evidence-based treatments which are effective in long-term smoking cessation, albeit that the actors are not necessarily socioeconomically disadvantaged (see page 446).
THE TERMINATOR....

No one would doubt the change in muscle bulk sported by the past Governor of California, Arnold Schwarzenegger, and indeed lack of activity would have led to such an anthropometric modification. Similarly, Husain and colleagues have shown prolonged controlled mechanical ventilation in humans triggers significant decreases in active and passive diaphragm myofibrillar force generation with a response that is mediated, in part, by impaired myosin cross-bridge kinetics and decreased myofibrillar protein levels (see page 436). This impairment of active and passive performance by diaphragm myofibrils as a result of increased degradation of essential myofilament proteins by the proteasome and autophagy proteolytic pathways. The clinical concept of ventilator induced diaphragm dysfunction is discussed in an accompanying editorial (see page 397). Just remember, we'll be back...

\section{RATTLESNAKES}

And finally... We shift seamlessly from film to music references, with a line from the song "Rattlesnakes" on Lloyd Cole's seminal 1984 album of the same name. "Her heart's like crazy paving, upside down and back to front..." In one of this month's images, it is the lungs, rather than the heart which are "like crazy paving" - though the aortic valve is calcified (see page 483). For those of you desperate for film references, the song goes on. "She looks like Eve Marie Saint in 'On the Waterfront'..." Enjoy our "Best of the US" Edition of Thorax!

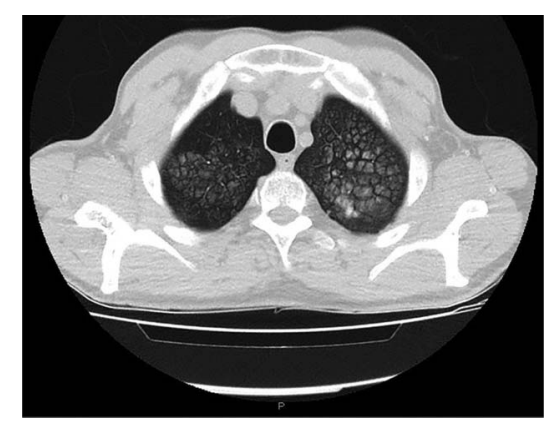

\section{REFERENCE}

1 Glantz SA, Kacirk KW, McCulloch C. Back to the future: Smoking in movies in 2002 compared with 1950 levels. Am J Public Health 2004;94:261-3. 